\title{
Posmodernidad. Elementos sociales vinculados con los jóvenes*
}

\author{
Joan Tahull** \\ Fidel Molina Luque** \\ Iolanda Montero****
}

Recibido: 7 de abril de 2015 - Revisado: 28 de mayo de 2015 -

Aprobado: 14 de agosto de 2015

Actualmente estamos instalados en la Posmodernidad. Este periodo se caracteriza por la complejidad, el desorden, las dificultades, las incertidumbres... Estos elementos están incrustados en toda la estructura social y cultural y no pueden reducirse a un ámbito específico. La realidad social no se presenta en compartimentos estancos, sino que todos los sectores están estrechamente relacionados. También los jóvenes reciben una influencia importante del entorno, y es este hecho en particular el que aborda este artículo, en orden a evidenciar el contexto y lo periférico que determina la identidad de los jóvenes. Sin presentarlo de forma directa, nos iremos acercando progresivamente al objeto de estudio, en relación con el cual se precisan algunos acontecimientos históricos relevantes y los elementos teóricos necesarios para comprender las transformaciones acaecidas. Esta información aparentemente tangencial se hace imprescindible para entender los procesos sociales seguidos de los últimos años.

Palabras clave: joven, dificultades, complejidad y relaciones sociales.

\footnotetext{
* $\quad$ Artículo de reflexión.

** Doctor en Sociología por la Universidad de Lleida, Licenciado en Filosofía y en Antropología Social y Cultural. profesor departamento de Sociología y Geografía de la Universidad de Lleida. Miembro del Grup d'Estudis sobre Societat, Salut, Educació i Cultura - GESEC. Dirección postal: calle Divina Pastora 1 Balaguer (Lleida) 25600, correo electrónico: joantfort@geosoc.udl.cat

*** Fidel Molina Luque. Catedrático de Sociología de la Universidad de Lleida. Miembro del Grup d'Estudis sobre Societat, Salut, Educació i Cultura - GESEC. Dirección postal: avenida Estudi General 4 Lleida 25001 (España), correo electrónico: molina@geosoc.udl.cat

**** Antropóloga y psicopedagoga. Profesora de secundaria, Generalitat de Catalunya. Dirección postal: calle Divina Pastora 1 Balaguer (Lleida) 25600, correo electrónico: ymontero@xtec.cat
} 


\title{
Postmodernity. Social elements related to young people*
}

\author{
Joan Tahull* \\ Fidel Molina Luque \\ Iolanda Montero****
}

\section{A bstract}

Nowadays we are living in the Postmodernity. This period is recognized by its complexity, its disorder, the (its) difficulties and uncertainties. These aspects or elements are fixed in all the social and cultural structure and so they can't be though as related only with an specific context. The social real life does not exist as separated contexts without connections and evolution, on the contrary, they are all closely related. Young people today get also an important influence from their cultural and social scene. In this article we will show the context and settings that cause (fix, determine) the identity of young people. Without going through directly the topic we will approach it gradually. We will display some relevant historical events and the necessary theoretic elements to understand the changes that took place (happened). This tangential information is essential to understand the social evolution (processes) during last years.

Keywords: Young, difficulties, complexity and social relationship.

\footnotetext{
* Reflection article.

** Doctor in Sociology from University of Lleida, Bachelor of Philosophy and Social and Cultural Anthropology. Professor in the Department of Sociology and Geography at the University of Lleida. Member of the Grup d'Estudis sobre Societat, Salut, Educació i Cultura - GESEC. Postal Address: calle Divina Pastora 1 Balaguer (Lleida) 25600, e-mail: joantfort@ geosoc.udl.cat

*** Fidel Molina Luque. Professor of Sociology at the University of Lleida. Member of the Grup d'Estudis sobre Societat, Salut, Educació i Cultura - GESEC. Postal address: avenida Estudi General 4 Lleida 25001 (Spain), e-mail: molina@ geosoc.udl.cat

**** Anthropologist and psychopedagogist. High school teacher, Generalitat de Catalunya. Postal address: calle Divina Pastora 1 Balaguer (Lleida) 25600, e-mail: ymontero@xtec.cat
} 


\title{
Postmodernisme. Éléments sociaux liés aux jeunes*
}

\author{
Joan Tahull* \\ Fidel Molina Luque \\ Iolanda Montero***
}

Actuellement nous sommes installés dans le Postmodernisme. Cette période se caractérise par la complexité, le désordre, les difficultés, les incertitudes... Ces éléments sont insérés dans toute la structure sociale y culturelle y ils ne peuvent se réduire à un domaine spécifique. La réalité sociale ne se présente pas en compartiments «étanches », mais au contraire tous les secteurs sont étroitement liés. Les jeunes sont également très influencés par leur environnement, et c'est ce fait en particulier qu'aborde cet article, dans le but de mettre en évidence le contexte et la périphérie qui détermine l'identité des jeunes. Sans le présenter de manière directe, nous nous approcherons progressivement à l'objet de l'étude, en relation duquel se déterminent certains faits historiques importants et les éléments théoriques nécessaires pour comprendre les transformations survenues. Cette information apparemment tangentielle se fait indispensable pour comprendre les processus sociaux continus des dernières années.

Mots clés: Jeune, difficultés, complexité et relations sociales.

\footnotetext{
* Article de réflexion.

** Docteur en Sociologie de I'Université de Lleida, Titulaire d'une Maîtrise en Philosophie et en Anthropologie Sociale et Culturelle, professueur du département de Sociologie et Géographie de I'Université de Lleida. Membre du Grup d'Estudis sobre Societat, Salut, Educació i Cultura - GESEC. Adresse postale: calle Divina Pastora 1 Balaguer (Lleida) 25600,e-mail: joantfort@geosoc.udl.cat.

*** Fidel Molina Luque. Professeur de Sociologie à I Université de Lleida. Membre du Grup d'Estudis sobre Societat, Salut, Educació i Cultura - GESEC. Adresse postale: avenida Estudi General 4 Lleida 25001 (Espagne), e-mail: molina@ geosoc.udl.cat.

**** Anthropologue y psicopédagogue. Professeur au collége, Generalitat de Catalunya. Adresse postale: calle Divina Pastora 1 Balaguer (Lleida) 25600, e-mail: ymontero@xtec.cat.
} 
La Posmodernidad se inicia a finales del último tercio del siglo XX. Esta terminología ha sido utilizada anteriormente en diferentes ámbitos: artístico, social, cultural, histórico, filosófico...; hasta que Lyotard, en 1979, publicó la obra La condición posmoderna y popularizó el concepto. El autor francés presentó las características fundamentales del periodo. Los autores posteriores hicieron referencia a esta obra clave para definir el nuevo contexto social y cultural. Se utilizó para corregir o matizar determinadas tesis. También para profundizar algunas afirmaciones e inspirar nuevas reflexiones a propósito del significado de Posmodernidad. Este movimiento abraza el conjunto de la sociedad. Tiene una relación directa con cualquier hecho social. No tiene que ser interpretado como un aspecto de una temática específica, sino que influye en toda la estructura social y cultural. También determina la identidad de los niños, adolescentes y jóvenes.

En este artículo mostraremos los principales elementos sociales de dicho periodo, haremos referencia a las características más destacadas, y principalmente, nos centraremos en los jóvenes. La forma como se adaptan e integran en la estructura social y cultural. La forma de desarrollar esta investigación será indirecta. Sin hacer una referencia clara y directa en los adolescentes, el tema se irá desarrollando tangencialmente. Presentaremos el entorno y lo periférico que construye y determina sus características. Estos elementos son claves, configuran y definen el objeto de estudio abordado. Sin un conocimiento adecuado, no se puede comprender la situación actual de los jóvenes.

Para tener un conocimiento profundo de esta temática se hace imprescindible analizar los principales elementos del periodo. También, conocer algunos hechos históricos claves que han determinado la sociedad actual.

Los autores que han reflexionado y escrito sobre la Posmodernidad destacan las dificultades para definir el concepto de forma consensuada. Diferentes intelectuales discuten a propósito del significado de lo posmoderno, desde diferentes puntos de vista. Enfatizan determinados elementos como los más representativos. Baudrillard (1992, 1993, 2000 y 2001) reflexiona en referencia a la importancia de la televisión como elemento fundamental en la construcción de la identidad del individuo; McLuhan (1985, 1998 y 2005) destaca el concepto de la globalización para hacer referencia a la característica fundamental de esta etapa; Castells $(2001,2005$ y 2009) analiza las conexiones de las nuevas tecnologías con las interacciones sociales; Beck (1998, 2002 y 2007) habla del concepto de riesgo en sentido amplio para caracterizar la sociedad actual; Bauman (2003, 2006 y 2007) destaca el concepto de líquido como elemento principal de los tiempos actuales y las relaciones sociales entre individuos.

Las discusiones entre diferentes sociólogos para interpretar este momento histórico se hacen especialmente complejas y difíciles. Hay un debate vivo e intenso. Se debe tener en cuenta la inmediatez. Todavía no hay la distancia suficiente para analizarlo objetivamente. Aunque, se pueden apuntar determinadas variables, las cuales se irán desarrollando progresivamente en el presente artículo. 
Diferentes elementos que los investigadores tienen en cuenta, aunque en grado diferente, para mostrar los elementos fundamentales de la Posmodernidad. La globalización; las nuevas tecnologías, especialmente la televisión e internet; cambios del modelo económico, principalmente el desarrollo acelerado del capitalismo; nuevas relaciones contractuales de los trabajadores, precariedad laboral, subcontratación, desempleo; las migraciones; el consumo; también, la relevancia de la publicidad y la importancia de la imagen; cambios en la estructura familiar, nuevos tipos de familias; el individualismo; el placer, la importancia de la imagen personal, el propio cuerpo; la pérdida de referentes sociales, culturales, religiosos y políticos; las minorías étnicas; la inmediatez, en relación con la pérdida del significado objetivo del pasado y futuro (el individuo vive en un eterno presente) y otros elementos.

Los investigadores sociales destacan la incertidumbre, la complejidad, la dificultad, la contradicción y un grado más elevado de riesgos que en etapas anteriores. Conceptos como incertidumbre y riesgo son utilizados de forma reiterada por investigadores para caracterizar la sociedad actual.

La situación presente exige tener en cuenta diferentes hechos históricos recientes, por su relevancia, para entender la situación actual. Se darán unas pinceladas generales, las cuales ayudarán a comprender el presente.

La Segunda Guerra Mundial dejó un mundo polarizado, Occidente, dominado por los Estados Unidos, y el bloque comunista, liderado por la URSS. La confrontación entre los dos países duró hasta 1989, cuando el régimen soviético se hundió. Sus diferencias iban más allá de las simples divergencias, eran dos modelos culturales, sociales y económicos distintos. De un día para otro, el sistema soviético, y todo lo que representaba, quedó aniquilado. Esta situación fue especialmente traumática en los países comunistas, ya que vivieron un largo proceso de desorden y fragmentación. Diferentes repúblicas se independizaron. Los países de la órbita soviética siguieron el mismo camino. Todo un modelo social y cultural perdió la supremacía. "El modelo capitalista, representado principalmente por los Estados Unidos, surgió, repentinamente, sin competencia y alternativa" (Roberts, 2009, p. 324).

También, a lo largo de estos años, la tecnología se desarrolló de forma extraordinaria. Se produjo un proceso de globalización y se abrían nuevas posibilidades. Las nuevas tecnologías transformaron radicalmente la sociedad. Estas dinámicas estuvieron influidas por una ideología capitalista dominante. Roberts (2009) afirma:

Es difícil encontrar en la historia de la tecnología una ola de innovación que haya entrado con tanto ímpetu. (...) El ejemplo más obvio es el de las $<$ computadoras $>$ o procesadores de datos electrónicos, cuyos primeros modelos aparecieron ya en 1945. Los rápidos aumentos de potencia y velocidad, las reducciones de tamaño y las mejoras de la capacidad de visualización supusieron un enorme incremento en la cantidad de información que se podía ordenar 
y procesar en un tiempo dado. En este caso, además, el cambio cuantitativo trajo consigo una transformación cualitativa. Ciertas operaciones técnicas hasta entonces inviables por la cantidad de datos implicados dejaron de serlo. Nunca se había acelerado tanto la actividad intelectual (p. 175).

La revolución de las nuevas tecnologías comenzó después de la Segunda Guerra Mundial. Este proceso no se frenó, al contrario, fue creciendo progresivamente. Actualmente, para pensar la sociedad es necesario tener en cuenta el desarrollo tecnológico.

También, los sucesos de mayo de 1968 son fundamentales para comprender la Posmodernidad. Durante la década anterior, la economía había mejorado significativamente y las condiciones de vida eran mejores. En este contexto, jóvenes estudiantes y otros colectivos salieron a la calle pidiendo cambios radicales y un modelo social y económico diferente. En aquel momento, los ciudadanos tenían más posibilidades, pero consideraban la estructura social caduca, rígida, estancada y alienante. Algunos autores consideraban la sociedad unidimensional (Marcuse, 1990). Esta solamente desarrollaba unas potencialidades concretas del individuo, la perspectiva más práctica, utilitaria y economicista. Por el contrario, castraba el ámbito de la libertad, la espontaneidad y la felicidad. Los hechos acaecidos en Mayo del 68 significaron abrir nuevos caminos, mostrar nuevos paradigmas:

Junto a los temas sociales y políticos fueron apareciendo en un proteico conglomerado un conjunto de cuestiones y aspiraciones. (...) Los estudiantes jugaron un papel relevante, los jóvenes trabajadores también, pero cabe señalar como más novedoso que las mujeres se hicieron visibles en las movilizaciones de París, Berkeley, Berlín o Madrid. A esa galaxia de contestatarios, rebeldes e insurgentes, les unía, eso sí, una idea: el mundo y la vida podían cambiar. Les unía la esperanza. Era cuestión de intentarlo. El 68 es la brecha por la que entraron nuevos actores y nuevos argumentos. El feminismo, el pacifismo y el ecologismo de < segunda generación > encuentran su hábitat para desarrollarse precisamente a partir de unas revueltas que, en principio, no los tenían como prioritarios (Garí, Pastor y Romero, 2008, p. 300).

El Mayo del 68 permitió a diferentes sensibilidades aparecer en el espacio público. Subculturas y movimientos contraculturales, hippies y otros, exigían un modelo social y cultural más plural y abierto. Reivindicaban superar el modelo capitalista y consumista. Las manifestaciones tuvieron consecuencias políticas, hicieron tambalear el gobierno francés. Estas protestas tuvieron repercusiones en todo el mundo. Diferentes países occidentales, Estados Unidos, Alemania, también España, en diferente intensidad, se manifestaron en contra de un modelo político y económico limitador del individuo. Los jóvenes pedían más democracia, pluralismo y libertad. 
Para comprender el individuo, se debe analizar el contexto social y cultural. Postman (1993) realiza interesantes aportaciones relacionando estructura, comunicación e individuo. El medio construye el sujeto y el imaginario social. Una comunidad, en la cual la forma prioritaria de comunicación se realiza alrededor del fuego, tiene unas características concretas. La imprenta abrió nuevas posibilidades a los individuos y también determinó el tipo de comunicación. La televisión marcó una nueva era, abrió nuevos caminos, y determinó nuevas formas de interaccionar entre individuos. Postman introduce un ejemplo ilustrativo de este periodo. Reagan, el presidente norteamericano, no tenía una sólida formación intelectual y política. Únicamente tenía una larga experiencia como actor de westerns. Postman (1993) lo expresa de esta forma:

\begin{abstract}
¿Qué virtudes se atribuyen a la política de Ronald Reagan? El mundo del espectáculo no está desprovisto de la idea de excelencia, pero su principal propósito es agradar al espectador y su instrumento es el artificio. Si la política sigue la lógica del espectáculo, entonces la idea no es perseguir la excelencia, la claridad y la honestidad, sino que lo parezca, lo cual es una cosa diferente. Esto se puede expresar mediante un solo concepto: la publicidad. (...) Pero no todo, el hecho de la venda de un presidente es sorprendente y degradante, solamente es una parte de algo más amplio: en América, la metáfora fundamental del discurso político es el anuncio de televisión (p. 159).
\end{abstract}

El sociólogo norteamericano considera que Reagan nunca hubiese llegado a presidente en otra coyuntura. Actualmente, los contenidos significativos pasan necesariamente el filtro de los medios audiovisuales, se tienen que vulgarizar y amenizar. Vivimos en la sociedad del entretenimiento y el show. "Lo fundamental es pasarlo bien" (Postman, 1993, p. 161).

Estos hechos, y más que no podemos desarrollar por no ser el objetivo fundamental del artículo, cristalizaron a lo largo de los años 80, y especialmente, en los 90, un nuevo paradigma social y cultural. El capitalismo se extendió por el mundo, sin obstáculos importantes. Conceptos como globalización, precariedad laboral, competencia, desempleo, publicidad, individualismo, consumismo... se desarrollaron en los países occidentales. Estos elementos anteriormente también estaban, pero con la caída del Muro de Berlín tuvieron más intensidad y radicalidad. Este cambio de modelo tuvo importantes repercusiones sociales y culturales. Provocaron cambios en los ámbitos laborales, familiares, comunitarios, políticos... Esta situación también apareció en España, aunque hubo un desajuste temporal en relación con otros países. La dictadura de Franco ralentizó las diferentes transformaciones sociales. Con la muerte del dictador y la llegada de la democracia, los españoles se integraron rápidamente al modelo capitalista occidental. España asumió con toda intensidad los valores occidentales. Los ciudadanos tuvieron que adaptarse a conceptos como complejidad, relativismo, fragmentación, pluralidad, tolerancia... 
La Posmodernidad, en los años 80 y 90, tuvo la característica fundamental de la globalización, interpretada como un proceso inevitable. El desarrollo de la tecnología, especialmente los mass media, señaló el camino a seguir. La globalización económica hace referencia a la importancia del mercado. No se reduce a lo local o regional, sino mundial. Los potenciales consumidores son los habitantes de cualquier lugar del mundo. Los fabricantes, como nunca antes, tienen la posibilidad de llevar sus productos de una parte del mundo a otra, en tiempo reducido y un precio competitivo. Durante los años 80,90 y el nuevo milenio aparece un nuevo concepto importante, la deslocalización. Las multinacionales pueden instalar sus factorías en países mucho más competitivos, donde las condiciones económicas son más favorables. Se establecen nuevas relaciones contractuales entre los trabajadores y los empresarios. Se amplía el ámbito de influencia en las decisiones empresariales. El cierre de una planta industrial en un lugar, no sigue necesariamente la lógica de la misma factoría, responde en muchos casos, a cuestiones globales. Son decisiones complejas que tienen en cuenta intereses comerciales, políticos, económicos, fiscales, medioambientales internacionales... Los trabajadores, muchas veces, se sienten desconcertados, desorientados y confusos. Las decisiones empresariales responden una lógica global, internacional, más allá de lo más próximo, lo local. Los países desarrollados tienen que adaptarse a esta nueva realidad económica, social y cultural. El Estado del Bienestar progresivamente se va desmantelando. Los trabajadores pierden poder adquisitivo y las condiciones laborales son cada vez más exigentes. La globalización ha entrado en nuestra casa. Beck (2007) habla de precarización de las condiciones laborales e introduce el concepto de brasileñización de la economía:

La consecuencia involuntaria de la utopía neoliberal del libre mercado es la brasileñización de Occidente. Lo que más llama la atención en el actual panorama laboral a escala mundial no es solo el elevado índice de paro en los países europeos, el denominado milagro del empleo en Estados Unidos o el paso de la sociedad del trabajo a la sociedad del saber, es decir, qué aspecto tendrá en el futuro el trabajo en el ámbito de la información. Es, más bien, el gran parecido que se advierte en la evolución del trabajo en el denominado primero y tercer mundo. Estamos asistiendo a la irrupción de lo precario, discontinuo, impreciso e informal en ese fortín que es la sociedad del pleno empleo en Occidente. Con otras palabras: la multiplicidad, complejidad e inseguridad en el trabajo, así como el modo de vida del sur en general, se están extendiendo a los centros neurálgicos del mundo occidental. En un país semiindustrializado como Brasil (...) la mayoría vive en unas condiciones laborales precarias. Abundan los vendedores ambulantes, los pequeños comerciantes y los pequeños artesanos... (p. 10).

El sociólogo alemán describe una comunidad donde el trabajo de calidad es un bien escaso y muy buscado. La economía informal tiene mucho peso. El modelo económico de los países semiindustrializados llega a los más desarrollados, se adapta mejor a la nueva coyuntura. La precarización y la desregularización 
de las condiciones laborales se extienden por Occidente y permite competir globalmente a las empresas. El individuo vive permanentemente en un estado de riesgo, incertidumbre y dudas. Estos elementos determinan una diversidad de condiciones contractuales del trabajador. Actualmente, por ejemplo, ser profesor dice poca cosa de la situación laboral del profesional. La relación contractual con la institución puede variar de forma substancial. Dependiendo del vínculo: interino, sustituto, media jornada, un tercio de jornada, trienios, estadios, funciones directivas, funcionario, laboral... determinan su retribución y relación con la institución. Estas diferencias tienen consecuencias, una de ellas hace referencia a la solidaridad entre el colectivo. Se hace mucho más difícil. Los intereses y motivaciones de los docentes son diferentes y, en algunos casos, pueden ser contradictorios. En el mismo colectivo profesional hay una gran variedad y pluralidad de necesidad y objetivos. El grupo pierde cohesión en la lucha por las reivindicaciones laborales; por el contrario, cada vez más, el trabajador negocia individualmente sus condiciones laborales y económicas. "Hay una pérdida del sentido colectivo" (Giddens, 2000, p. 182).

El modelo capitalista está estrechamente relacionado con el consumismo y la publicidad. La globalización facilita el consumo de productos de todas las partes del mundo. Bienes exóticos difíciles de encontrar años atrás, actualmente son de fácil consumo para la mayoría. La globalización económica permite que el ámbito de actuación de las empresas sea todo el mundo. La competencia ha aumentado de forma exponencial. El ciudadano occidental tiene una enorme presión para consumir. Las multinacionales utilizan la publicidad para exhibir sus productos. Muchas veces utilizan estrategias irracionales y emotivas para que el consumidor relacione una marca con una emoción o sentimiento: felicidad, alegría, libertad, placer, autenticidad... Los publicistas han investigado tenazmente para desarrollar estrategias comerciales más eficaces. Este campo está abierto y en constante evolución. El éxito de una campaña publicitaria tiene la potencia de impulsar definitivamente un producto. El ámbito estético y formal tiene una importancia fundamental en las estrategias comerciales. El ciudadano vive en un estado de abundancia de mensajes publicitarios. Muchos de ellos transmiten la idea relacionando consumo y felicidad. Bauman (2008) lo expresa de la siguiente manera:

La sociedad consumista se justifica con la promesa de saciar los deseos como ninguna sociedad anterior se planteó hacerlo. La promesa de la satisfacción solamente continúa siendo seductora mientras el deseo está insatisfecho, mientras el cliente no está completamente satisfecho. (...) La sociedad consumista prospera en la medida que consigue hacer perpetua la no-satisfacción de sus miembros (la infelicidad de los individuos) (p. 68).

Según el autor, las multinacionales buscan saciar unas necesidades que ellas mismas han creado mediante la publicidad y nunca solucionan del todo. Los ciudadanos son bombardeados con mensajes relacionando consumo y felicidad. Se obtiene satisfacción al instante de consumir, aunque dura poco. Cuando se finaliza el acto de consumir, el individuo vuelve a sentir la necesidad de comprar 
más, solamente para saciar el deseo. El consumismo crea la necesidad, cuando ha terminado la compra, el sujeto vuelve a sentir el impulso de repetir. Este modelo busca la no-satisfacción de los sujetos, una perpetua infelicidad. Se crea una necesidad eterna de consumir. Por este motivo, algunos individuos realizan compras compulsivas. Necesitan consumir constantemente para sentirse bien. Algunas personas tienen relaciones patológicas con el mercado.

Estos elementos sociales y culturales no pueden reducirse a un lugar específico, aparecen en todos los países, en diferente intensidad. La globalización ha tenido la capacidad de extender determinados hechos sociales. Por ejemplo, la globalización de los productos alimentarios (pizzas italianas, cuscús de los países del Magreb, pescado de Chile, guacamole y burritos de México, hamburguesas de EUA, salsas tailandesas, sushi japonés...), productos tecnológicos (teléfonos móviles, internet, portátiles, ebooks, iPad...), modelos culturales (moda, música, espectáculos...), arquitectura (rascacielos, grandes zonas comerciales...), etc. La globalización construye un mundo cada vez más parecido. Sujetos de diferentes lugares del mundo, muy diferentes y alejados entre ellos, comparten los mismos alimentos, tecnologías, entretenimiento... Espectáculos globales como la NBA, la Champions Leage, la Fórmula 1 o cantantes como Beyoncé, Lady Gaga, Madonna y otros, van más allá de un público específico o una zona concreta, son espectáculos mundiales. Tienen una relevancia internacional de primera magnitud. Sus fans, en todos los países, conocen las peculiaridades del artista. Las diferencias culturales específicas van cambiando progresivamente hacia rasgos globales. El entretenimiento, la moda, la arquitectura... pierden progresivamente las características locales y asimilan las universales. Los pueblos pierden su idiosincrasia y adquieren elementos generales. Lo micro cada vez es más parecido a lo macro. Lo local presenta más similitudes hacia lo global. Las diferencias entre el ámbito rural y urbano se van difuminando.

La tecnología ha tenido una influencia directa en la concepción del espacio y el tiempo. Actualmente, la distancia física entre las personas no es un grave problema. La tecnología permite un contacto constante. Permite comunicarse a mucha distancia. El desarrollo tecnológico ha transformado la visión tradicional del espacio y el tiempo. Castells (2005) hace la siguiente reflexión:

El tiempo y el espacio, al igual que sucede con otros aspectos de nuestra vida, se entiende y plantea en la actualidad de un modo diferente a como se asumían en el pasado. La razón de ese cambio consiste, principalmente, en la expansión de un nuevo sistema electrónico, caracterizado por su alcance global, su integración de todos los medios de comunicación y su interactividad potencial. Este cambio permite la articulación potencial de textos, imágenes y sonido en el mismo sistema, interactuando desde puntos múltiples, en un tiempo elegido (real o demorado) a lo largo de una red global, con un acceso abierto y asequible (pp. 360-361).

Las nuevas tecnologías han provocado cambios sustanciales en las interacciones sociales entre individuos. Modelos comunes, utilizados años atrás, actualmente 
no son usados, se interpretan caducos. Continuamente, aparecen nuevos productos en el mercado que mejoran y superan los anteriores. La transformación de la sociedad es profunda, compleja y difícil de valorar. Este modelo ha venido para quedarse, aunque, no podamos ponderar exactamente como es, tampoco hacer proyecciones adecuadas del futuro. Las nuevas tecnologías crean la ilusión de satisfacer cualquier ilusión, ahora y aquí. Conceptos como futuro, paciencia y espera pierden la relevancia de tiempos pretéritos. El individuo vive en un estado de conexión permanente. Hay un desplazamiento de la realidad. El mundo real es el virtual.

Las nuevas tecnologías son instrumentos utilizados por la mayoría de los ciudadanos, pero si un colectivo se ha apropiado de forma decidida y radical en su uso, son los más jóvenes. En muchos casos, su vida puede interpretarse como una continua intercomunicación, mediante el móvil, el correo electrónico, el whatsApp, el Facebook... Los sociólogos reflexionan sobre la forma de utilizar las tecnologías por los jóvenes. Sarabia y De Miguel muestran una imagen típica de interacciones sociales entre adolescentes:

Hablando de comunicación, un miembro de esa sociedad líquida, de diecinueve años, en Barcelona, señala que internet y el teléfono móvil < dan una gran libertad de palabra a las personas ya que la presencia física de otra persona delante de ti (o su voz) coarta tu voluntad de decirle según qué. Gracias a internet y al móvil es mucho más fácil hablar de amor, de la vida y la muerte, de sexo, de temas tabú o sencillamente importantes. Una vez que lo has hecho con una persona a través de internet, resulta más fácil volver a hacerlo, pero esta vez cara a cara. Yo diría que mi generación tiene mucha más facilidad a la hora de hablar de temas como estos que las generaciones que la han precedido $>$. A través de internet-y-móvil se compromete poco y se sufre poco. Se conecta y se desconecta con facilidad. Se dice que en el hielo fino la vida del patinador depende de la velocidad. Lo mismo ocurre con las conexiones por la red o por ondas: la calidad se sustituye por la cantidad. Lo importante es cuántos mensajes se reciben al cabo del día, no tanto lo que se comunica. El estilo es $<$ Me gustaría hablar contigo, cuando puedas. Necesito oír tu voz...>. Los dramas se producen cuando los mensajes supuestamente enviados a una persona se envían a otra por error. Es cuando se suele descubrir que las personas jóvenes están jugando a máscaras con varias personas al mismo tiempo. La mentira es moneda corriente, quizás porque nadie cree realmente en la realidad que se falsifica. Se miente para sobrevivir, pero se miente tanto que, no se sabe la frontera entre la realidad y la ficción (Iglesias de Issel, 2005, p. 659).

Los jóvenes se socializan con las nuevas tecnologías. Interactúan y viven de forma diferente a las generaciones pasadas. Esta situación provoca desconcierto y confusión en muchos adultos. Muchas veces, estos no comprenden la importancia del móvil, internet... para ellos. Hay una separación entre padres e hijos, 
también, profesores y alumnos. Un abismo social y cultural, el cual progresivamente se va ensanchando. Los adultos no comprenden su necesidad irresistible de estar conectados constantemente. Para los adolescentes, estos recursos son más que entretenimiento, lo consideran instrumentos básicos de comunicación. No tener móvil representa un inconveniente, limita las posibilidades de relación con sus iguales. Entonces, no están en una situación de igualdad con sus compañeros. No pueden dar ni recibir información. Este elemento puede ser significativo para no estar integrado al grupo. Actualmente, la comunicación cara a cara de los jóvenes ha perdido importancia. Muchos lo consideran excesivamente violento. Por contra, las nuevas tecnologías permiten expresar lo más íntimo. Actualmente, es frecuente observarlos en los espacios públicos, plazas, en silencio, sin hablar un largo tiempo. Simplemente, están escuchando música con los auriculares y enviando mensajes con el móvil. Muchos a amigos no presentes, pero otros a compañeros que están allí mismo. Los adultos consideran estas interacciones sociales incomprensibles; en cambio, para ellos es una normalidad. Consideran la comunicación más sencilla y fluida mediante las nuevas tecnologías.

La construcción de la identidad de los jóvenes depende de las nuevas tecnologías. También, es importante tener en cuenta la familia. Tradicionalmente, este era el agente fundamental en la formación de la personalidad del niño. A su alrededor pivotaba el desarrollo social, psicológico y afectivo de los hijos. En la Posmodernidad, la familia ha tenido cambios importantes. Para muchos está en un proceso de crisis. También, se han multiplicado las opciones de organización familiar.

Elzo (2004) realiza una investigación y elabora una tipología de las familias españolas. Fundamentalmente, hay cuatro tipos: la endogámica (23.7 \% de las familias españolas), la conflictiva (15\%), la nominal (42.9\%) y la adaptativa $(18.4 \%)$.

Siguiendo con el autor vasco, en la familia endogámica, las responsabilidades de los miembros son claras y asumidas sin dificultades. El estatus y los roles están bien definidos. Todos saben el lugar que ocupan dentro de la familia. Las relaciones entre padres e hijos son buenas. Valoran positivamente hacer cosas juntos y tienen capacidad para adaptarse a las novedades. Los padres transmiten los valores a los hijos, principalmente valores finalistas, como la moralidad, buena educación y la importancia del dinero. La segunda tipología hace referencia a la familia conflictiva. Los miembros tienen una relación mala entre ellos, hay conflictos. Las dificultades vienen por diferentes temas: drogas, amigos, relaciones conflictivas entre hermanos... En esta tipología familiar, la relación entre padres e hijos es la peor. La comunicación de los miembros del núcleo familiar es muy pobre o nula. La capacidad socializadora es claramente negativa para los jóvenes, llegando a extremos de construcción de valores antinómicos. La tercera tipología familiar es la nominal. Este es el modelo mayoritario en nuestra sociedad. La coexistencia es pacífica. Los miembros se comunican poco, para evitar conflictos. No hay convivencia participativa, no hacen o hacen 
pocas actividades juntos. Todos van a su aire. Los padres están cohibidos, no implicados en temas familiares. No tratan en profundidad los temas que preocupan a los jóvenes. Los adultos buscan su tranquilidad, su realización personal. Elzo la define como familia light. El cuarto y último modelo es la familia adaptativa. Esta tipología busca adaptar la familia a las nuevas condiciones sociales y culturales; también, a los nuevos roles del hombre, la mujer y los hijos. Este modelo presenta una buena comunicación entre padres e hijos, hay confianza. Hay capacidad de expresar las opiniones, creencias y valores. Esta familia es abierta e intenta estar bien informada. Este constante esfuerzo de adaptación conlleva, en algunos casos, conflictos; pueden ser graves, debido al hecho que están continuamente en revisión y cambio. Elzo (2004) detecta principalmente estas cuatro tipologías familiares en España.

El sociólogo, en el artículo citado, introduce un listado, por orden de preferencia de los valores finalistas, de más a menos importancia por los jóvenes. Estos destacan la importancia de relaciones familiares afectuosas y cálidas, con una nota de 8.5 de un máximo de 10. Los hijos dan mucha importancia a la familia, al hecho de tener confianza. Ellos desearían hablar con sus padres, de sus cosas, pero en muchas ocasiones, los adultos les cierran las puertas. Para muchos jóvenes es un deseo, un ideal y provoca frustración, rabia e inseguridad no tener la oportunidad. Para los adolescentes, la familia es una institución fundamental para la construcción de su identidad.

Elzo (2000) considera que muchas familias occidentales han dimitido de su función de criar y educar a sus hijos. Estos reciben una socialización fragmentaria y caótica, sin orden ni sentido:

Los jóvenes construyen su vida como si de un puzle se tratara, en efecto, con todo tipo de fichas, pero, y esto es capital, a diferencia de lo que sucede con los puzles en cuya tapa está el modelo a construir, muchos adolescentes no tienen modelo. Hacen el puzle sin tapa. Tienen las fichas, muchas fichas, pero construyen el puzle en gran medida a ciegas, tanteando, experimentando, quitando y poniendo piezas. Muy pocos lo terminan (p. 145).

Algunas familias no ofrecen una educación adecuada a sus hijos. Hasta pueden dimitir de sus funciones. Entonces, este vacío es ocupado por otros agentes de socialización, como el grupo de iguales. Los amigos siempre han tenido importancia en la construcción de la identidad social de los jóvenes. Entre ellos, se establecen unas interacciones de igual a igual, sin disciplina y sin el control adulto. El grupo de amigos es un ámbito fundamental para entenderlos. El joven aprende a partir del ensayo y error. Escogen y ensayan como quieren ser. En muchos casos, en su casa, el papel del adulto, padre y madre es una figura débil o inexistente. Algunos jóvenes no tienen unos referentes sociales y culturales claros. Se sienten perdidos, desorientados y vulnerables. Estos límites, referentes y normas difusas conlleva, en algunos casos, a situaciones de anomia. En este marco, algunos se sienten impulsados a desarrollar conductas extremas. Giddens 
(2000) destaca el hecho que el individuo posmoderno coquetea activamente con el riesgo, especialmente los jóvenes.

Muchos adolescentes responden en diferentes momentos de sus vidas compulsivamente. Estas conductas agresivas las realizan principalmente en situaciones de ocio. Por ejemplo, consumiendo drogas ilegales y legales, realizando conductas violentas y agresivas, mediante relaciones sexuales precoces... El alcohol y las drogas son dos temas presentes en nuestra sociedad y en los jóvenes es especialmente preocupante. Su acceso es fácil y cercano. Hasta, en algunas situaciones, es un recurso de socialización, para desinhibirse, para ser más auténticos y ser más ellos:

Se ha venido produciendo en las últimas décadas, en ese ámbito de globalización, una confluencia: los países del Norte añaden a sus hábitos tradicionales los del Sur (incorporan el vino, y con él el consumo diario), y muchos de los jóvenes de los países del Sur añaden a sus hábitos el de la búsqueda sistemática de la borrachera cada vez que salen, y con bebidas de alta graduación, como se suponía que hacían exclusivamente los del Norte. Encuestas realizadas en el marco de nuestra investigación en España se señalan cuatro conclusiones: 1) Los menores beben alcohol más frecuentemente; 2) Los jóvenes que beben, beben más alcohol por sesión; 3) En general estas tendencias son mucho más pronunciadas para las chicas; 4) Altos niveles en el uso de alcohol son asociados con el uso de tabaco y drogas ilegales (Baigorri y Fernández, 2004, p. 80).

Este fragmento muestra la relación entre el aumento de consumo de alcohol y el ocio y entretenimiento. Existe una conexión entre borrachera y pasarlo bien. En muchos casos, para el joven, el sábado por la noche tiene sentido si beben mucho, fuman mucho y consumen drogas ilegales. También, resulta interesante destacar del texto anterior el punto 3, el cual hace referencia a las chicas. Ellas han aumentado el consumo de alcohol y sustancias ilegales. Muchas tienen un consumo parecido o superior a los chicos. La sociedad actual se puede definir por el conflicto, la complejidad y las contradicciones. Según Feixa (2008), algunos jóvenes responden a este modelo social mediante conductas extremas.

Lo social no está cerrado y aislado en unos determinados ámbitos, sino ahora más que nunca existe una evidente y constante retroalimentación entre diferentes ámbitos, sectores e instituciones. Para entender a los jóvenes es fundamental analizar la estructura social y cultural. También, conocer los principales hechos históricos. Se establece una relación entre sociedad, familia e individuo. La influencia de los tres ámbitos es radicalmente desigual. Nunca, menos ahora, los jóvenes se tienen que estudiar separados de lo social. No se puede entender su identidad sin tener en cuenta las características de la Posmodernidad.

Este artículo presenta el marco general que permite situar los principales elementos de la sociedad posmoderna. No pretende ofrecer un análisis exhaustivo, sino mostrar las coordenadas generales para situar las principales características 
de la Posmodernidad. Estos elementos están incrustados en la estructura social y cultural. La globalización y las nuevas tecnologías son aspectos de primera magnitud para entender las transformaciones que están sucediendo. Los cambios son rápidos e imprevisibles y no conocemos la evolución de los mismos. Los segmentos de la población más vulnerables sufren con más intensidad esta inestabilidad. Los jóvenes, principalmente, se encuentran en un periodo de la vida especialmente indefinido y difuso. Para muchos de ellos, el tránsito hacia la edad adulta es especialmente traumático y difícil. Las clases sociales más desfavorecidas sufren más radicalmente la complejidad, los riesgos y la incertidumbre intrínseca de la Posmodernidad. Especialmente, los hijos de los sectores sociales más humildes.

\section{Referencias}

Baigorri, A., y Fernández, R. (2004). Botellón. Un conflicto postmoderno. Barcelona: Icaria editorial.

Baudrillard, J. (1992). El sistema de los objetos. México: Siglo XXI.

Baudrillard, J. (1993). Cultura y simulacro. Barcelona: Kairós.

Baudrillard, J. (2000). Pantalla total. Barcelona: Anagrama.

Baudrillard, J. (2001). La Guerra del Golfo no ha tenido lugar. Barcelona: Anagrama.

Bauman, Z. (2003). Modernidad líquida. México: Fondo de Cultura Económica.

Bauman, Z. (2006). Vida líquida. Barcelona: Paidós.

Bauman, Z. (2007). Els reptes de l'educació en la modernitat líquida. Barcelona: Arcadia.

Bauman, Z. (2008). Vida de consum. Barcelona: Viena.

Bazarra, L., y García, J. (2004). Ser profesor y dirigir profesores en tiempos de cambio. Madrid: Narcea.

Beck, U. (1998). La sociedad del riesgo: hacia una nueva modernidad. Barcelona: Paidós.

Beck, U. (2002). La sociedad del riesgo global. Madrid, España: Siglo XXI Editores. 
Beck, U. (2007). Un nuevo mundo feliz: la precariedad del trabajo en la era de la globalización. Barcelona: Paidós.

Castells, M. (1997). La era de la información: economía, sociedad y cultura. Barcelona: Editorial UOC.

Castells, M. (2001). La galaxia internet. Barcelona: Plaza \& Janés.

Castells, M. (2005). La sociedad del conocimiento. Barcelona: Editorial UOC.

Castells, M. (2009). Comunicación y poder. Madrid: Alianza.

Elzo, J. (2000). El silencio de los adolescentes: lo que no cuentan a sus padres. Madrid: Temas de hoy.

Elzo, J. (2004). La educación del futuro y los valores. Barcelona: UOC. [Versión en línea] Disponible en http://www.uoc.edu/dt/esp/elzo/elzo0704.pdf

Elzo, J. (2006). Los jóvenes y la felicidad: ¿Dónde la buscan? ¿Dónde la encuentran? Madrid: PPC.

Feixa, C. (2008). De jóvenes, bandas y tribus. Barcelona: Ariel.

García, A., y Sánchez, A. M. (2005). Drogas, sociedad y educación. Murcia: Universidad de Murcia.

Garí, M. (comps.) (2008). 1968: El mundo pudo cambiar de base. Madrid: Los libros de la Catarata.

Giddens, A. (2000). Un mundo desbocado: los efectos de la globalización en nuestras vidas. Madrid: Taurus.

Gomis, J. (2001). Un sueño de igualdad. Madrid: Los libros de la Catarata.

Iglesias de Ussell, J. (comps.) (2005). Leer la sociedad: una introducción a la sociología general. Madrid: Tecnos.

Lyotard, J. F. (1994). La condición postmoderna: informe sobre el saber. Madrid: Cátedra.

Marcuse, H. (1990). El hombre unidimensional: ensayo sobre la ideología de la sociedad industrial. Barcelona: Ariel.

McLuhan, M. (1985). Guerra y paz en la aldea global. Barcelona: Planeta-Agostini.

McLuhan, M. (1998). La galaxia Gutenberg. Barcelona: Círculo de Lectores. 
McLuhan, M. (2005). La aldea global: transformaciones en la vida y los medios de comunicación mundiales en el siglo XXI. Barcelona: Gedisa.

Postman, N. (1993). Divertim-nos fins a morir. El discurs públic a l'época del "Show Business". Badalona: Llibres de l'índex.

Roberts, J. M. (2009). Historia universal. Tomo IV: de la Primera Guerra Mundial a la actualidad. Barcelona: RBA.

Tahull, J., y Montero, I. (2013). Fundamentos de la Posmodernidad. Limitaciones de la educación. Revista Arena de Argentina, 3(1).

Tahull, J., y Montero, I. (2013, septiembre). Reflexionando sobre el concepto de autoridad. Revista de la Asociación de sociología de la Educación, 6(3).

Vinyamata, E. (2009). Derechos humanos, nuevas realidades. Barcelona: UOC. 